\title{
Analysis Effect of Exhaust's Temperature, Total of Peltier's Element and Circuit Type for Thermoelectric Generator Output Voltage at Exhaust Internal Combustion Vehicle
}

\author{
Irwan Setyowidodo ${ }^{1}$, Achmad Tri Fadhila ${ }^{1}$, Am. Mufarrih ${ }^{1}$
}

\begin{abstract}
This research based on researcher observation about internal combustion vehicle energy percentage, there is 40\% energy flow away as high temperature exhaust gas. That percentage could converted as electricity energy with thermoelectric generator concept using peltier element. Purpose of this research are (1) getting optimum exhaust's temperature to produce highest voltage, (2) getting optimum total of peltier elemen to produce highest voltage, (3) getting optimum circuit type to produce highest voltage, (4) getting optimum Seebeck coefficient point. This research is using $L_{20}$ orthogonal matrix with three replication and design experiment factorial method. Independent variable that varied are exhaust's temperature, total of peltier element and circuit type. Response variable in this research is output voltage that analyzed with Anova and contrast test (Scheffe's method). This research's result and conclusion is all combination that run simultaneous giving an effect at thermoelectric generator's voltage, in Anova result. Based on main effect plot and contrast test, optimum combination factor for highest voltage are $240^{\circ} \mathrm{C}$ exhaust's temperature, four peltier element in series circuit. Highest Seebeck coefficient at 0,0524 V/K. From this research, researcher suggest thermoelectric generator implimentation at exhaust internal combustion vehicle to use factor combination $240^{\circ} \mathrm{C}$ exhaust's temperature, four peltier element in series circuit.
\end{abstract}

Keywords-Circuit type, Exhaust's Temperature, Peltier Element, Thermoelectric Generator.

\section{INTRODUCTION}

Vehicle that using internal combustion concept is most dominate vehicle in the world. But energy efficiency on this concept still low. From 100\% fuel energy percentage, 30\% energy used for engine operation, $5 \%$ for friction, $25 \%$ for mobility and $40 \%$ flow away as exhaust gas [1]. This $40 \%$ energy percentage in exhaust gas as a thermal energy with high temperature could converted become electricity energy with thermoelectric generator (TEG) using peltier element that connected electrically as a main component.

Purpose of this research are (1) getting optimum exhaust's temperature to produce highest voltage, (2) getting optimum total of peltier elemen to produce highest

\footnotetext{
${ }^{1}$ Irwan Setyowidodo, Achmad Tri Fadhila, Am. Mufarrih are with Department of Mechanical Engineering, Faculty of Engineering, Universitas Nusantara PGRI Kediri, Kediri 64112, Indonesia. E-mail: achmadtrifadhila@gmail.com.
}

voltage, (3) getting optimum circuit type to produce highest voltage, (4) getting optimum Seebeck coefficient point.

\section{LITERATURE REVIEW}

\section{A. Peltier element}

Peltier element is a component in generally use peltier principle, if there is a electricity current flowed on peltier element will proceeds heat transfer [2]. Peltier element construction consisted of (1) thermoelectric peltier element legs, (2) ceramic plate that insulate peltier legs, (3) electric conductor, (4) electric wire [2]. Illustration of peltier element conctruction shown on figure below.

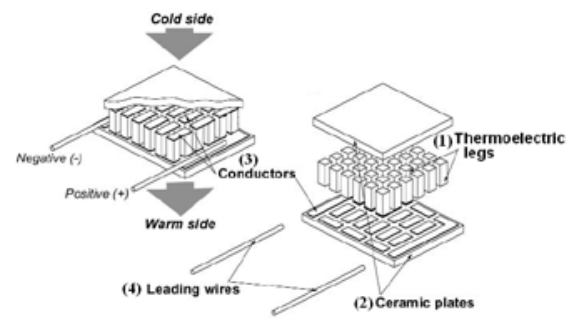

Figure 1. Peltier element construction.

\section{B. Thermoelectric Generator}

Thermoelectric generator (TEG) is system that based on Thomas Johann Seebeck theory (1826), if two semiconductor material have temperature difference on each surface it will produce voltage [2]. This condition known as Seebeck effect that discribed by formula:

$$
S=\frac{V}{\Delta T}
$$

$S$ is Seebeck coefficient $(\mathrm{V} / \mathrm{K}), V$ as a voltage that produced by thermoelectric generator (volt) and $\Delta T$ is temperature difference between two side of peltier [3].

Process to produce a voltage started by peltier legs with two type semiconductor material is n-type and p-type. Electron on side of legs that heated up have higher thermal energy. Electron with higher thermal energy will spread to side of legs with lower temperature (cold side). Atom neutrality in constant condition so electron distribution composse negative load at cold side and positive load at hot side, this phenomenon will produce electricity voltage [4]. 
The $3^{\text {rd }}$ International Seminar on Science and Technology August $3^{\text {rd }}$ 2017, Postgraduate Program Institut Teknologi Sepuluh Nopember, Surabaya, Indonesia

\section{Energy percentage on internal combustion vehicle}

In generally energy percentage on internal combustion vehicle around on 30\% energy used for engine operation, $5 \%$ for friction, $25 \%$ for mobility and $40 \%$ as exhaust gas [1], this statement can illustrated on figure below:

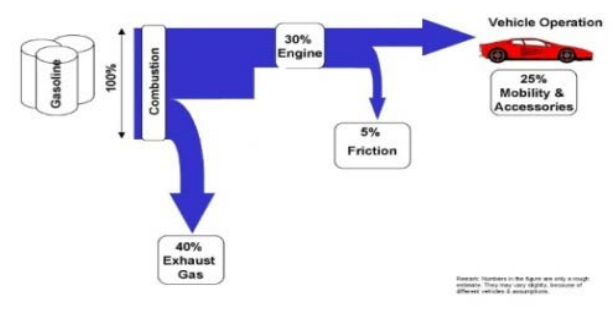

Figure 2. Internal combustion energy percentage.

\section{Contrast test (Scheffe's method)}

Purpose of Contrast test (Scheffe's method) is to determine optimum factor with compare group of contrast value and critical value [5]. This method require standard error with formulation:

$$
S c_{u}=\sqrt{M S_{E} \sum_{i=1}^{a}\left(c_{1 u}^{2} / n_{i}\right)}
$$

$M S_{E}$ as mean square of error, $c_{1}^{2}$ as contrast group and $n_{i}$ as total observation [5]. Beside that, critical value is require too with formulation:

$$
S_{\alpha . u}=S c_{u} \sqrt{(a-1) F_{\alpha a-1 N-a}}
$$

$\mathrm{Sc}_{\mathrm{u}}$ is standard error for contrast group data, $\alpha-1$ as degree of freedom and $F_{\alpha-1 N-\alpha}$ as F table value [5].

\section{METHOD}

This research use faktorial experiment method with three factor (Independent variable) that run simultaneous in three replication. Three factor itself shown on table below:

TABLE 1.

THIS RESEARCH'S FACTOR.

\begin{tabular}{ccc}
\hline \hline $\begin{array}{c}\text { Exhaust's } \\
\text { Temperature }\end{array}$ & Total of Peltier & Circuit Type \\
\hline $\mathrm{a} 1=200^{\circ} \mathrm{C}$ & $\mathrm{b} 1=2$ pieces & $\mathrm{c} 1=$ series \\
$\mathrm{a} 2=210^{\circ} \mathrm{C}$ & $\mathrm{b} 2=4$ pieces & $\mathrm{c} 2=$ parallel \\
$\mathrm{a} 3=220^{\circ} \mathrm{C}$ & - & - \\
$\mathrm{a} 4=230^{\circ} \mathrm{C}$ & - & - \\
$\mathrm{a} 5=240^{\circ} \mathrm{C}$ & - & - \\
\hline \hline
\end{tabular}

All factor will combined simultaneously to determine the effect on thermoelectric generator output voltage that implemented on internal combustion vehicle exhaust. The combination with factorial method are shown below.

TABLE 2.

FACTOR COMBINATION (FACTORIAL METHOD).

\begin{tabular}{cc}
\hline \hline Number of Experiment & Factor Combination \\
\hline 1 & a1b1c1 \\
2 & a1b2c1 \\
3 & a1b1c2 \\
4 & a1b2c2 \\
5 & a2b1c1
\end{tabular}

$\begin{array}{cc}6 & \text { a2b2c1 } \\ 7 & \text { a2b1c2 } \\ 8 & \text { a2b2c2 } \\ 9 & \text { a3b1c1 } \\ 10 & \text { a3b2c1 } \\ 11 & \text { a3b1c2 } \\ 12 & \text { a3b2c2 } \\ 13 & \text { a4b1c1 } \\ 14 & \text { a4b2c1 } \\ 15 & \text { a4b1c2 } \\ 16 & \text { a4b2c2 } \\ 17 & \text { a5b1c1 } \\ 18 & \text { a5b2c1 } \\ 19 & \text { a5b1c2 } \\ 20 & \text { a5b2c2 }\end{array}$

Based on table 2 shown all factor combination in this experiment that symbolized with alphabetical. First combination is a1b1c1, it means this combination use thermoelectric generator with $200^{\circ} \mathrm{C}$ exhaust's temperatur, two pieces peltier element that connected in series.

Dimention (size) for thermoelectric generator in this research for two pieces peltier hot heat sink is $10 \mathrm{~cm} \mathrm{x} 8$ $\mathrm{cm}$, meanwhile for four pieces peltier hot heat sink is $19 \mathrm{~cm}$ x $8 \mathrm{~cm}$. Dimention for cold heat sink using constant size at $25 \mathrm{~cm} \times 12 \mathrm{~cm}$. Design of this thermoelectric generator is shown figure below.

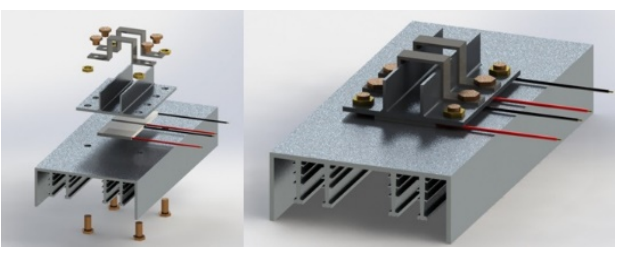

(a)

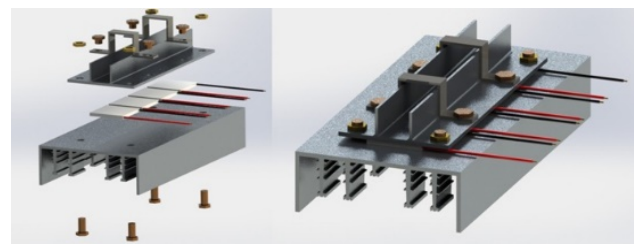

(b)

Figure 3. (a) TEG 2 pieces peltier (b) TEG 4 pieces peltier.

Meanwhile for thermoelectric generator that already install on internal combustion vehicle exhaust pipe is shown ther figure below.

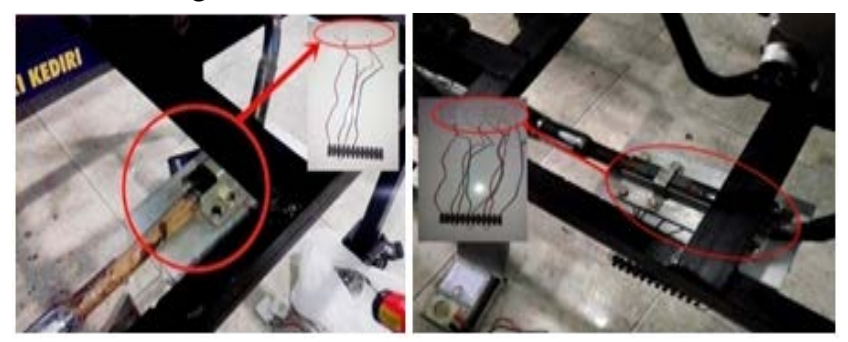

Figure 4. (a) TEG installation for 2 pieces peltier (b) TEG installation for 4 pieces peltier. 
Research data obtained from measurement instrument, for exhaust's temperature and heat sink temperature is measured by infrared thermometer. For output voltage obtained by analog multitester. Measurement method shown on figure below.

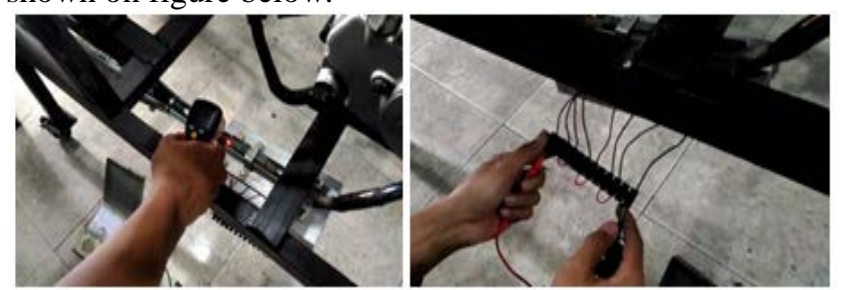

Figure 5. (a) Temperature scan (b) Voltage measurement.

\section{RESUlt AND DiSCUSSION}

In this research, researcher make a test on thermoelectric generator with low electricity load to prove that TEG can producing voltage as shown figure below.

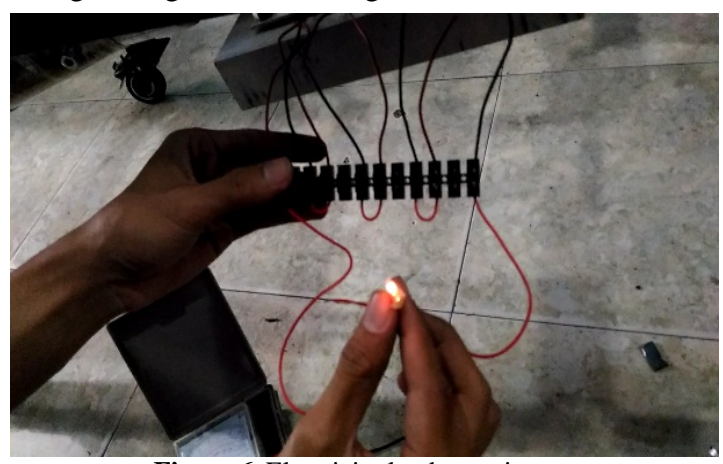

Figure 6. Electricity load experiment.

On the figure 6 shown that researcher use a low voltage LED lamp that connected directly with thermoelectric generator as a electricity load experiment.

From research result, researcher obtain thermoelectric generator output voltage data for all combination factor that design before with factorial method. Output voltage data will become main data that will analyzed with analysis of variance to determine that all factor can give an effect simultaneously or not to thermoelectric generator output voltage. After analysis of variance, researcher will compare the P-value with significant level of error $(\alpha=5 \%)$, if Pvalue lower than $\alpha$ that indicate all factor give an effect on thermoelectric generator output voltage. Secondly for recheck the result, researcher will compare $F$ value from analysis of variance with $\mathrm{F}_{\alpha}$ from distribution table $\mathrm{F}$ 0,05. If $F$ value from analysis of variance is higher from $F_{\alpha}$ it will convice that all factor really give an effect on thermoelectric generator. Here output voltage data for this research.

TABLE 3.

TEG OUTPUT VOLTAGE DATA

\begin{tabular}{ccccc}
\hline \hline \multicolumn{4}{c}{ Research's Factor } \\
No & $\begin{array}{c}\text { Circuit } \\
\text { Type }\end{array}$ & $\begin{array}{c}\text { Total of } \\
\text { Peltier }\end{array}$ & $\begin{array}{c}\text { Exhaust's } \\
\text { Temperature }\end{array}$ & $\begin{array}{c}\text { V Out } \\
\text { (Volt) }\end{array}$ \\
\hline 1 & Series & 2 & $200^{\circ} \mathrm{C}$ & 1,13 \\
2 & & & $210^{\circ} \mathrm{C}$ & 1,6
\end{tabular}

\begin{tabular}{cccc}
3 & & $220{ }^{\circ} \mathrm{C}$ & 2,06 \\
4 & & $230{ }^{\circ} \mathrm{C}$ & 2,6 \\
5 & & $240{ }^{\circ} \mathrm{C}$ & 2,8 \\
\hline 6 & & $200{ }^{\circ} \mathrm{C}$ & 1,6 \\
7 & & $210{ }^{\circ} \mathrm{C}$ & 2,2 \\
8 & 4 & $220{ }^{\circ} \mathrm{C}$ & 2,8 \\
9 & & $230{ }^{\circ} \mathrm{C}$ & 3 \\
10 & & $240{ }^{\circ} \mathrm{C}$ & 3,4 \\
\hline 11 & & $200{ }^{\circ} \mathrm{C}$ & 0,6 \\
12 & & $210{ }^{\circ} \mathrm{C}$ & 0,8 \\
13 & 2 & $220{ }^{\circ} \mathrm{C}$ & 1 \\
14 & & $230{ }^{\circ} \mathrm{C}$ & 1,2 \\
15 & & $240{ }^{\circ} \mathrm{C}$ & 1,4 \\
16 & Parallel & $200{ }^{\circ} \mathrm{C}$ & 0,8 \\
17 & & $210{ }^{\circ} \mathrm{C}$ & 1 \\
18 & & $220{ }^{\circ} \mathrm{C}$ & 1,2 \\
19 & & $230{ }^{\circ} \mathrm{C}$ & 1,4 \\
20 & & $240{ }^{\circ} \mathrm{C}$ & 1,6 \\
\hline \hline
\end{tabular}

Based on data table 3, researcher can arrange graphs for thermoelectric generator output voltage as shown below.

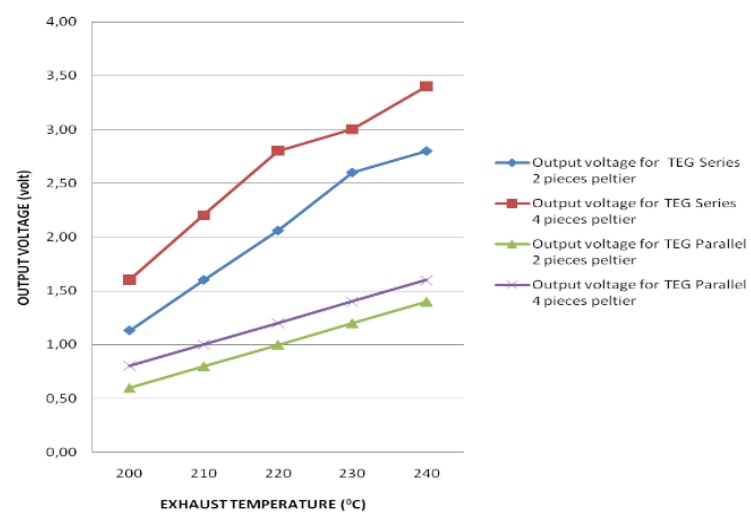

Figure 7. Graphs for output voltage.

From figure 7, indicate that thermoelectric generator with four peltier in series circuit produce highest voltage than others combination factor. Beside of output voltage graphs, researcher obtain Seebeck coefficient graphs too for all factor in three replication experiment as shown below.

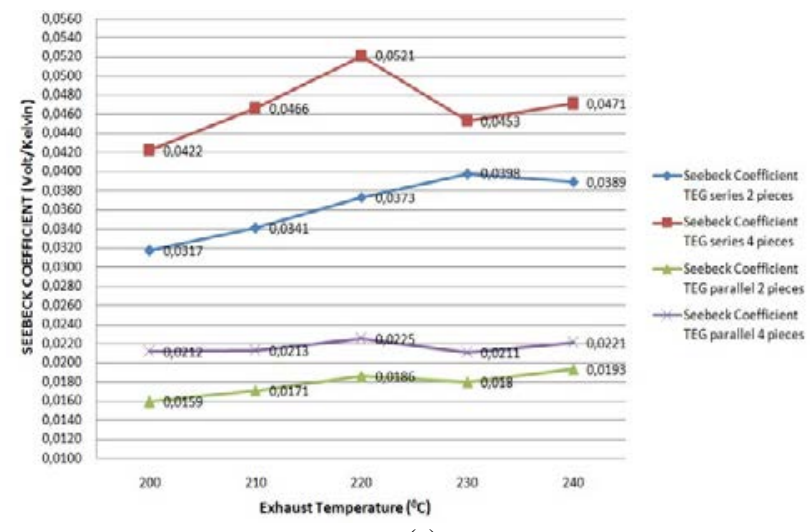

(a) 


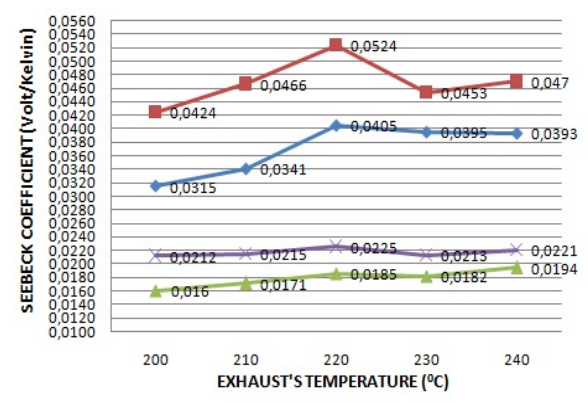

(b)

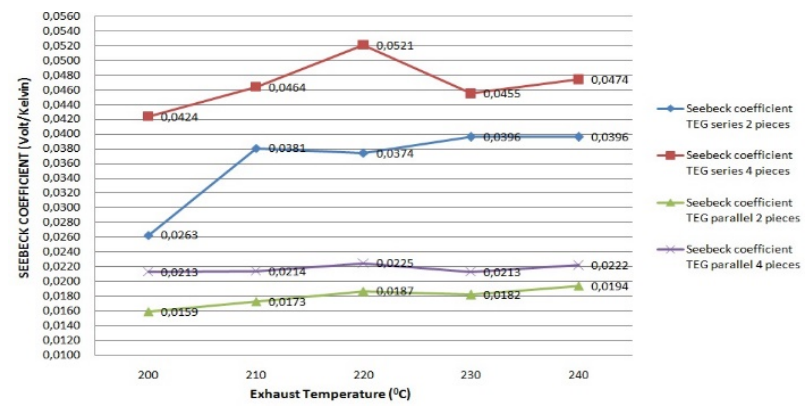
(c)

Figure 8. (a) Graphs for seebeck coefficient first experiment (b) Graphs for seebeck coefficient second experiment (c) Graphs for see beck coefficient third experiment.

Based on seebeck coefficient graphs figure 8 (a) thermoelectric generator can produce 0,0521 volt for 1 kelvin temperature difference on each side of peltier element as a highest data on first experiment. From figure 8 (b) thermoelectric generator produce highest coefficient as performance representation of thermoelectric generator around $0,524 \mathrm{~V} / \mathrm{K}$ with four peltier in series circuit on second experiment. It means if there is 1 kelvin as a temperature difference between two side of peltier it will generate 0,524 volt from thermoelectric generator. Based on figure 8 (c) the highest seebeck coefficient around 0,521 $\mathrm{V} / \mathrm{K}$ (samilar from first experiment).

After comparing three data on figure 8, known that the optimum seebeck coefficient around 0,524 V/K (highest than seebeck coefficient first experiment and seebeck coefficient third experiment)

Output voltage data as main data that will tested in analysis of variance, but firstly all output voltage data must qualify in three assumption test (normality test, identical test and independent test). The result of three assumption test is shown on figure 9 .

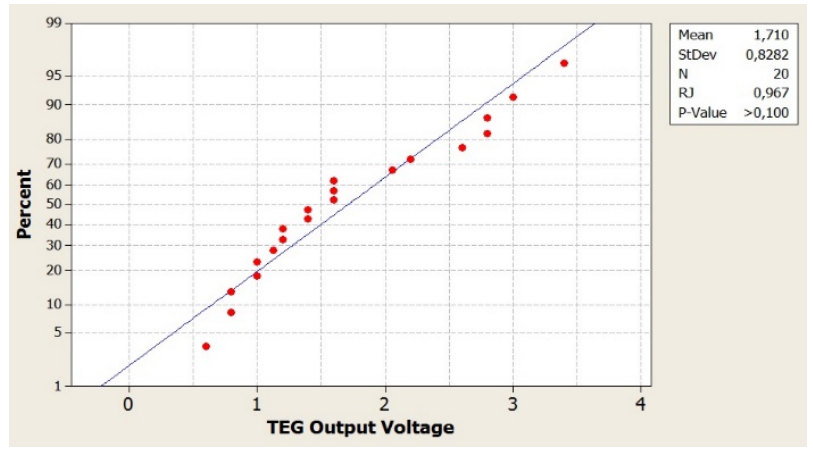

(a)

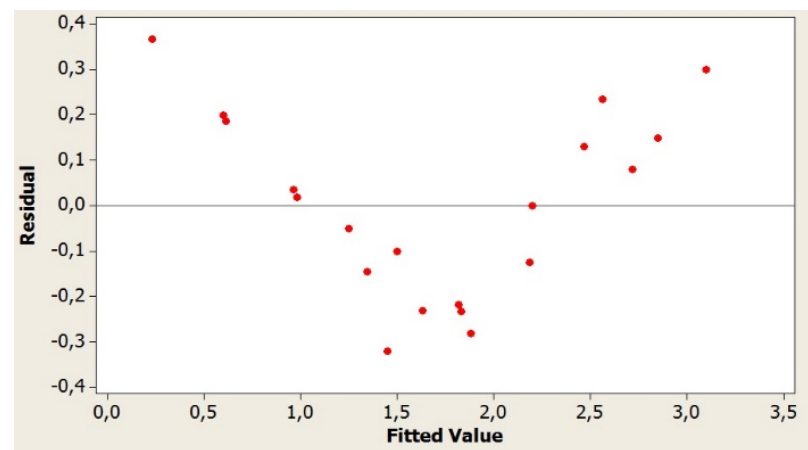

(b)

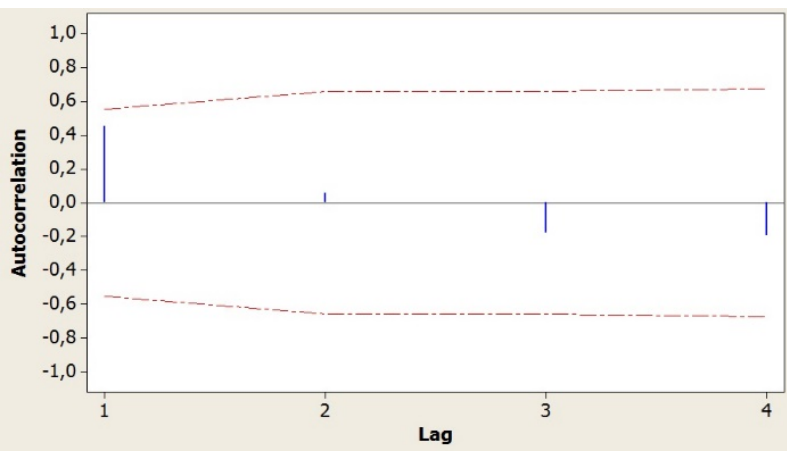

(c)

Figure 9. (a) Normality test result (b) Identical test result (c) Independent test result.

On the figure 9 (a) shown the result of normality test, based on Ryan Joiner's normality test method indicate that all data qualify on normality test with P-value 0,100 and higher than $\alpha=5 \%$ as significant level of error in this research. Then the second assumption test is identical test that the result is shown on figure 9 (b). On figure 9 (b) shown that all residual data was distributed randomly around zero value. This indicate that all data already qualify identical assumption as a main data. Move on third assumption test that shown on figure 9 (c). Researcher use autocorrelation fuction (ACF) to determine the result of independent test. On the figure 9 (c) the ACF value (blue vertical line) not passed through the independent line (red line). This result indicate that all output voltage data qualify independent assumption.

After output voltage data qualify on assumption test, they will tested on analysis variance to determine that all factor in this experiment give an effect on thermoelectric generator output voltage. The result of analysis is shown on the table below.

TABLE 4.

ANALYSIS VARIANCE RESULT

Analysis of Variance for Rata-Rata Output Voltage, using Adjusted SS for Tests

\begin{tabular}{lccccc}
\hline \multicolumn{1}{c}{ Source } & DF & Seq SS & Adj MS & F & P \\
\hline Circuit Type & 1 & 7,42 & 7,42 & 122,3 & 0,000 \\
Total of Peltier & 1 & 0,72 & 0,72 & 11,9 & 0,004 \\
T. Exhaust & 4 & 4,08 & 1,02 & 16,8 & 0,000 \\
Error & 13 & 0,78 & 0,06 & & \\
Total & 19 & 13,0 & & & \\
\hline \hline
\end{tabular}


This research itself use $\alpha=5 \%(0,05)$ as significant lavel of error. This significant level will compared with P-value from output analysis of variance on table 4 . From table 4 shown that all P-value $<\alpha=0,05$ (lower than significant level), this result emphasize that there is an effect from all research factor to generate output voltage on thermoelectric generator.

Second step is comparing F-value with $\mathrm{F}_{\alpha}(\mathrm{a}-1)(\mathrm{N}-\mathrm{a})$ from distribution table $\mathrm{F}$. Value of $\mathrm{F}_{0,05}$ (2) (57) for this experiment is 3,16 . The comparison is shown on the table below.

TABLE 5.

F-VALUE COMPARISON

\begin{tabular}{cccc}
\hline \hline Research Factors & F-value & & $\mathbf{F}_{0,05}$ \\
\hline Circuit Type & 122,3 & $>$ & 3,16 \\
Total of Peltier & 11,9 & $>$ & 3,16 \\
T. Exhaust & 16,8 & $>$ & 3,16 \\
\hline \hline
\end{tabular}

From the table 5, known that all research factor have higher F-value than $\mathrm{F}_{0,05}$ (from distribution table $\mathrm{F}$ ). This indicate and proved that all factor can give an effect on thermoelectric generator for produce electricity voltage. Beside that, the contribution percentage for each factor is shown below.

TABLE 6.

CONTRIBUTION PERCENTAGE EACH FACTOR.

\begin{tabular}{lccccc}
\hline \hline $\begin{array}{c}\text { Research } \\
\text { Factors }\end{array}$ & DF & Seq SS & Adj MS & SS' & $\begin{array}{c}\% \\
\text { Contribution }\end{array}$ \\
\hline Circuit Type & 1 & 7,4298 & 7,4298 & 7,369 & 56,54 \\
Total of & 1 & 0,7258 & 0,7258 & 0,665 & 5,10 \\
Peltier & 4 & 4,0873 & 1,0218 & 3,8441 & 29,50 \\
T. Exhaust & 13 & 0,7898 & 0,0608 & & 8,86 \\
\hline Error & 19 & 13,0327 & & & 100,00 \\
Total & & &
\end{tabular}

From the table 6, known that circuit type give higher contrbution as a factor with $56,54 \%$, temperature exhaust become second strong factor with $29,50 \%$ and at the last total of peltier with $5,10 \%$. Value contribution percentage for error for this research factor is around 8,86\% (lower that $10 \%)$, this percentage indicate that all factor in this research are main factor that give effect on thermoelectric generator output voltage.

To determine optimum factor, researcher use Contrast test (Scheffe's method). First researcher compare data between series and parallel circuit with two pieces peltier from data table 2, the result from first contrast test is shown below.

TABLE 7.

CONTRAST TEST SERIES AND PARALLEL CIRCUIT WITH TWO PIECES PELTIER.

\begin{tabular}{ccccc}
\hline \hline$\Gamma$ & $|C|$ & & $\mathbf{S}_{0,05}$ & Result \\
\hline$\mu_{1}-\mu_{11}$ & 0,53 & $>$ & 0,502 & Contrast \\
$\mu_{2}-\mu_{12}$ & 0,8 & $>$ & 0,502 & Contrast \\
$\mu_{3}-\mu_{13}$ & 1,06 & $>0,502$ & Contrast \\
$\mu_{4}-\mu_{14}$ & 1,4 & $>0,502$ & Contrast \\
$\mu_{5}-\mu_{15}$ & 1,4 & $>0,502$ & Contrast \\
\hline \hline
\end{tabular}

Based on table 7 known that thermoelectric generator with two peltier in series circuit (data $\mu 1-\mu 5$ ) become more optimum to produce voltage than using parallel circuit. After that, researcher compare data between series and parallel with four peltier, the result shown below.

TABLE 8.

CONTRAST TEST SERIES AND PARALLEL CIRCUIT WITH FOUR PIECES PELTIER.

\begin{tabular}{ccccc}
\hline \hline$\Gamma$ & $|C|$ & & $\mathbf{S}_{0,05}$ & Result \\
\hline$\mu_{6}-\mu_{16}$ & 0,8 & $>$ & 0,502 & Contrast \\
$\mu_{7}-\mu_{17}$ & 1,2 & $>$ & 0,502 & Contrast \\
$\mu_{8}-\mu_{18}$ & 1,6 & $>0,502$ & Contrast \\
$\mu_{9}-\mu_{19}$ & 1,6 & $>0,502$ & Contrast \\
$\mu_{10}-\mu_{20}$ & 1,8 & $>$ & 0,502 & Contrast \\
\hline \hline
\end{tabular}

Based on table 8 known that thermoelectric generator with four peltier in series circuit (data $\mu 6-\mu 10$ ) become more optimum to produce voltage than using parallel circuit. At the last from contrast test (Scheffe method), researcher compare data between two and four pieces with series circuit as a highest data in this experiment, the result from contrast test is shown below.

TABLE 9.

CONTRAST TEST TWO AND FOUR PIECES PELTIER WITH SERIES CIRCUIT.

\begin{tabular}{ccccc}
\hline \hline$\Gamma$ & $|C|$ & & $\mathbf{S}_{0,05}$ & Result \\
\hline$\mu_{1}-\mu_{6}$ & 0,47 & $<$ & 0,502 & No \\
$\mu_{2}-\mu_{7}$ & 0,6 & $>0,502$ & Contrast \\
$\mu_{3}-\mu_{8}$ & 0,74 & $>0,502$ & Contrast \\
$\mu_{4}-\mu_{9}$ & 0,4 & $<0,502$ & No \\
$\mu_{5}-\mu_{10}$ & 0,6 & $>0,502$ & Contrast \\
\hline \hline
\end{tabular}

From the table 9 known that thermoelectric generator that use four peltier in series circuit become most optimum factor on $210{ }^{\circ} \mathrm{C}, 220^{\circ} \mathrm{C}$, and $240{ }^{\circ} \mathrm{C}$ exhaust's temperature (data $\mu 7, \mu 8, \mu 10$ ) than use four peltier in parallel circuit. This result confirm the result of main effect plot that plotted to support the result of contrast test. The main effect plot is shown below.

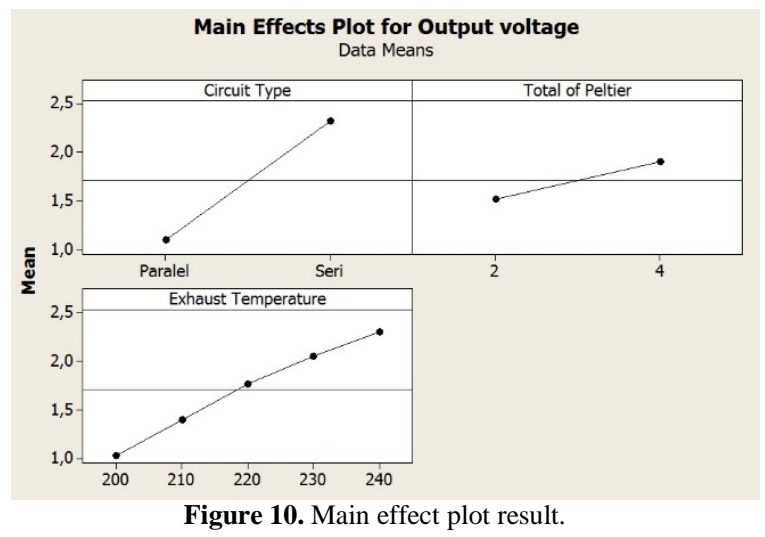

From figure 10, shown that thermoelectric generator with four peltier element in series circuit on $240{ }^{\circ} \mathrm{C}$ exhaust's temperature become combination optimum factor to produce higher voltage than others combination. 
The $3^{\text {rd }}$ International Seminar on Science and Technology

August $3^{\text {rd }}$ 2017, Postgraduate Program Institut Teknologi Sepuluh Nopember, Surabaya, Indonesia

From the result kwon that series circuit become more optimum than parallel circuit to produce voltage. This result strengthened by a theory when peltier element connected in series circuit it will produce higher voltage than parallel circuit (such as DC battery in series circuit) [4].

Based on research result, known that thermoelectric generator with four pieces peltier more optimum than two pieces peltier to generate voltage. This result strengthened by a theory thermoelectric multistage, that implementation peltier in more number of pieces will produce higher voltage than just use single peltier on thermoelectric generator [6]. Higher voltage can possible reached if there is a lot number of peltier leg (type-N and type-P) for higher electron flow between two side of peltier [7].

\section{CONCLUSION}

Based on the test results in this paper, the performance of the KNN classification is still very poor and cannot be applied directly to Itama's job. Further research is needed to improve the classification performance with the purpose of opinions anomaly detection. Further research can be done by the increasing the amount of research data and the using of another feature of public sector financial reports. This paper uses only 150 data and 9 features of financial statements, classification performance is expected to increase through the addition of the data amount and research features.

\section{ACKNOWLEDGEMENT}

We thank Badan Pemeriksa Keuangan Republik Indonesia or abbreviated BPK RI (The Audit Board of The Republic of Indonesia) for giving the school opportunity and providing access to research data, also very grateful to The Ministry of Communication and Informatics of The Republic of Indonesia for scholarships.

\section{REFERENCES}

[1] M. A. Karri, "Modeling of An Automotove Exhaust thermoelectric Generator," Clarkson University, 2005.

[2] A. Bitschi, "Modelling of thermoelectric devices for electric power generation," Technical University of Vienna, 2009.

[3] D. Yan, "Modeling and Application of a Thermoelectric Generator," University of Toronto, 2011.

[4] R. Brink, "Development of Miniature Personal Thermoelectric Regenator,” Dublin City University, 2004.

[5] D. C. Montgomery, Design and analysis of experiments. New York: John Wiley \& Sons, 2001.

[6] Melcor, Thermoelectric Handbook. Trenton: Laird Technologies, 2000.

[7] T. Sakamoto, Y. Suzuki, and T. Hirasawa, "Development of HighPower Large-Sized Peltier Module,” Furukawa Rev., vol. 27, pp. 9113, 2005. 